\title{
Sensitizing Nigerian Secondary School Teachers on the Available Web-Based Tools Suitable for Instructional Delivery in Christian Religious Studies
}

\author{
G. A. Kosoko-Oyedeko \\ School of Arts and Social \\ Sciences, Michael Otedola \\ College of Primary Education \\ (Mocped) Noforija Epe, \\ Lagos State, Nigeria
}

gaa oyedeko@yahoo.com

\author{
G. O. Adedoja \\ Faculty of Education, \\ Teacher Education \\ Department, \\ University of Ibadan, \\ Oyo State, Nigeria
}

sadedoja@yahoo.com

\section{Abstract}

Teaching with ICT has been reported yielding positive results by the way of improving academic performance nearly in all subjects' area. While many secondary school teachers are already making use of ICT to improve their teaching; many still lack awareness about the available ICT web based tools suitable for instructional delivery. This is particularly true of the secondary school Christian religious studies (CRS) teachers in Nigeria. In the light of this, the paper examined ICT web based tools for instructional delivery in CRS. A total of 500 secondary schools CRS teachers selected from 100 secondary schools in Lagos, Ogun and Oyo States in Nigeria represent the sample for the study. The results demonstrated that awareness of the CRS teachers is high on the suitability of email and Facebook than other web based tools. Some participants (60\%) have attempted using email to teach CRS while none of the participants have attempted using web based tools like drop box, newsgroup, RSS feeds, wiki, flikr and knowledge system. The most common obstruction to the use of the web based tools for CRS instructional delivery is electricity failure rate. The study recommends based on its findings that government should consider finding alternative to electricity failure rate as the study has indicated this as the most prominent factor limiting their awareness of the available web based tools suitable for teaching CRS. There is need to create more awareness on those tools the CRS teachers indicated having limited awareness of. This may inform of organising a workshop where the entire participants will be connected with the Internet. Through this, they will be exposed to those tools and practically see how they can be used.

Material published as part of this publication, either on-line or in print, is copyrighted by the Informing Science Institute. Permission to make digital or paper copy of part or all of these works for personal or classroom use is granted without fee provided that the copies are not made or distributed for profit or commercial advantage AND that copies 1) bear this notice in full and 2) give the full citation on the first page. It is permissible to abstract these works so long as credit is given. To copy in all other cases or to republish or to post on a server or to redistribute to lists requires specific permission and payment of a fee. Contact Publisher@InformingScience.org to request redistribution permission.
Keywords: ICT, Tools, Instructional delivery, Christian religious studies, Secondary school, Teachers, Nigeria.

\section{Introduction}

The use of ICT in education and training, teaching and instructional delivery has been a priority in most African countries during the last few years, but 
much progress has not been made. There are considerable differences of "e-readiness within and between countries, and between schools within countries. A small percentage of schools in some countries have embedded ICT into the curriculum, and demonstrate high levels of effective and appropriate ICT use to support and transform teaching and learning across a wide range of subject areas. Most schools in most developing countries such as Nigeria, however, are in the early phase of ICT adoption, characterised by patchy uncoordinated provision and use, some enhancement of the learning process, some development of e-learning, but no profound improvements in learning and teaching.

Teaching with ICT have been reported yielding positive results by the way of improving academic performance nearly in all subjects area. This is because ICT has turned from being a technology of communication and information to a curriculum creation and delivery system for teachers and learners. While many secondary school teachers are already making use of ICT to improve their teaching; many still lack awareness about the available ICT web based tools suitable for instructional delivery. This is particularly true of the secondary school CRS teachers in Nigeria. March (2005) reported that only a few educational institutions are taking advantage of the advancement of Web-based technology and have integrated current Web-based tools into their curricula. In the light of this, this paper examines ICT web based tools use for instructional delivery in Christian religious studies. It is expected that ICT tools such as email, discussion forum, drop box, news group, blog, etc, will be revealed as suitable ICT web based tools for CRS instructional delivery. These results will thereby intimate CRS teachers who are not yet aware of the relevance of these tools for teaching CRS in schools. Recommendations based on these results will be highlighted.

\section{Literature Review}

It is widely acknowledged that Information and Communication Technology (ICT) can be used to improve the quality of teaching and learning at any level of education. In fact, ICTs are becoming natural part of man's daily life; thus their use in education by teachers and students is becoming a necessity. Certainly, the present and future academic global community will utilise ICTs to a high degree. This has made it imperative that teachers not only need to use ICTs, but they need to become comfortable with using ICTs.

Information and Communication Technology (ICT) is defined as computer based tools used by people to work with the information and communication processing needs of an organisation. It encompasses the computer hardware and software, the network and several other devices (video, audio, photography camera, etc.) that convert information (text), images, sound, and motion, and so on into common digital form (Milken Exchange on Education Technology, 1999). It is an eclectic application of computing, communication, telecommunication and satellite technology (Yusuf, 2000). Teachers at all levels of education are usually involved basically in two things: teaching and research, with auxiliary administrative assignments. ICTs have the potentials of not only ensuring effectiveness and efficiency in these two areas (teaching and learning); they have the potentials of easing the administrative duties. These applications are further elucidated below.

\section{ICT as Instructional Delivery Tools}

As a tool, "ICT has the potential to transform the way that education is delivered" (Fisher 2001). ICT can facilitate differentiation and individualization in education: it makes it possible to tailor both the content and the presentation of the subject matter to the individual background, experience and needs of students. In addition, as Schiller \& Tillett (2004) said "ICT enhances what is possible by amplifying what teachers are able to do, by providing an entry point to content and enquiries that were not possible without the use of ICT, by extending what students are able to 
produce as a result of their investigations, and finally by providing teachers with the opportunity to become learners again."

According to the possibilities of utilizing ICT as a tool in education, its usage spread. " $92 \%$ of primary schools teachers make regular use of ICT for teaching and learning" (BECTA 2004) However, as indicated by Ofsted (2005) "In primary schools ICT was used mainly to support English and mathematics; there was some use of ICT in other subjects but application across the curriculum was still largely undeveloped."

\section{The Effect of Using ICT in Teaching Religious Subject}

Nowadays, schools or learning institute provide computer and IT as the learning material to gain knowledge and experience. Students now have more understanding during teaching process. Internet especially provides many kinds of information and also learning tools in educational lines. The objective of the exercise is to prepare them in solving problems. One of the methods is by using multimedia activities. Besides learning, the teachers can attract the students' interest in learning process and they understand more if they learn by using something that will attract their interest (Lubis, Embi., Yunus, \& Wekke, (2009). Therefore, by implementing ICT technologies in religious teaching process, it can improve the students' interest and also creative thinking. ICT plays some important roles which are to assist teachers in the teaching, provide them with tools to illustrate some points or processes as well as to support long distance educational system. On the part of the students, the importance of the ICT is to enable them to associate between concrete/ tangible facts from the abstract ones, to help promote the students' retention and to facilitate the Simulation and Recovery phases.

To support the use of ICT, it is important to upgrade teacher's specialization and skill so that they may identify, troubleshoot and overcome various related problems. The School Resource Centre is one of the units within a school functioning in the collection, processing, managing and offering of various administration and educational resources tools. With the establishment of these centres, the goal to upgrade the teaching and learning process in reproducing knowledgeable community may be achieved.

\section{ICT Web Based Tools and the Teaching of CRS}

Information and communication technologies (ICTs) now drive teaching and learning process. There are some ICT web based tools suitable for knowledge impartation and instructional delivery in CRS. Some of these tools include: E-mail, mailing lists, newsgroups, knowledge weblogs and knowledge systems.

\section{E-mail}

This is the most commonly used collaborative tool for communication. It is very popular for knowledge sharing, one-to-one or one-to- many. Knowledge is transferred and shared. The common term for "electronic mail", a method for writing, sending and receiving electronic text (and audio and/or video) over a computer network. A variation of email popular with mobile telephone users is the Short Messaging Service (SMS). Email differs to other messaging systems in that it is asynchronous in nature. _Strenski (1998) identified advantages of email as teaching tool as: Provides writing practice; easy submission of written work virtual "field trips" (WWW); virtual "guest speakers" (WWW) ; opportunity at large, faceless, institution for personal participation; student publication, especially collaborative work and models life-long learning in a democratic public forum

Strenski (1998) also provide the advantages of email to the instructors as: giant photocopier: easy to distribute and update curriculum materials (handouts, readings, study questions) giant P.A. sys- 
tem; extends office hours; extends classroom discussion; guarantees contact with individual students; provides date stamp for submission of work and provides unique learning spaces.

\section{Mailing List / Discussion Group}

It is an electronic discussion that anyone can subscribe to. A discussion group is an online forum for individuals to discuss various topics amongst each other. People add their comments by posting a block of text to the group. Others can then comment and respond. Discussion groups (also known as mailing lists) are used to send messages/information to a group of people with similar interests. A discussion group is controlled by a computer (mail server) which forwards a copy of any message it receives to those people who have chosen to join (subscribe) the discussion group. If a member of the discussion group (subscriber) contributes to a discussion group then the message sent will be forwarded to everyone else who is part of that discussion group. It is therefore a useful means of disseminating information to a particular group of people. Discussion groups are moderated so that messages are checked for suitability before being distributed to other members of the discussion group. Members of a discussion group can either receive messages as they are sent, or as a compilation of messages (digest) at the end of the day. This is very useful for creating sharing and transferring knowledge. Members of the group can discuss on any issue of concern. It is a major medium for KM process. It may be moderated or not.

\section{Newsgroups}

This is a group where exchange of information takes place. A newsgroup is a discussion about a particular subject consisting of notes written to a central Internet site and redistributed through Usenet, a worldwide network of news discussion groups. Usenet uses the Network News Transfer Protocol. There are many news groups on a variety of topics. Anyone can post messages to newsgroups. Membership is not necessary unlike the discussion groups where membership is mandatory.

Newsgroups are organized into subject hierarchies, with the first few letters of the newsgroup name indicating the major subject category and sub-categories represented by a subtopic name. Many subjects have multiple levels of subtopics. Some major subject categories are: news, (recreation), (society), (science), (computers), and so forth. Users can post to existing newsgroups, respond to previous posts, and create new newsgroups.

\section{Knowledge Weblogs}

This is a type of website where entries are made such as in a diary displayed in reverse chronological order. A blog consists of a title, headline, URL, post date and time. The person who updates a blog is called a blogger and their activity of updating is called blogging. When an author who is not a blogger edits the content of the postings it is called a wiki. Intranet blogging is a great way for new employees to pick the level of efficiency expected by an organization. Most organizations keep a weblog of their activities

The advantages of blog as teaching tool according to Klistrom (2009) can be summarised as follows: Students can $\log$ on at different times from different places other than with their teacher; Students will learn to summarize answers, clarify thoughts, and express them accurately; Teachers will have to have current links to information and can provide extra resources for students; Teacher focuses less on content delivery and more on student discovery; Blogging engages the students in a more effective way and will engage them over the entire course or class; and Real world problems may take on new and creative solutions, with the aid of a blog. 


\section{Knowledge Systems}

There are some websites which connects people to knowledge and ideas, retrieving data, respond to queries, etc, thereby creating innovation. Some of these knowledge systems are:

Imagine ware and Universal Knowledge Processor (UKP). Imagineware - This is a system that connects people to knowledge and ideas thereby creating innovation. It captures ideas, best practices and intellectual capital. The URL is: www. Imagineware.com. Universal Knowledge Processor (UKP) - This is a website for browsing and retrieval of data, etc, in the form of text, image and video. The system responds to queries by delaying related topics, and automatically discards irrelevant topics.

\section{Interactive Whiteboard}

An interactive whiteboard is simply a surface onto which a computer screen can be displayed, via a projector. It is touch-sensitive and lets you use a pen on it (or in some cases, a finger) to act like a mouse, controlling the computer from the board itself. Changes made to information projected onto the whiteboard are transferred to the computer and can be saved and retrieved in future lessons. Everything that can be displayed on a computer can be projected onto the whiteboard and, if the computer is linked to speakers and a DVD or video player, multimedia resources can be incorporated too. If the board is connected to the Internet, teachers can have immediate access to appropriate websites to enhance work in the lesson.

Also whorth mentioning are some Web 2.0 technologies or tools useful to facilitate knowledge impartation in the teaching and learning of CRS. Technologies in this categories include wikis, blogs and RSS feeds, social networking tools (e.g., Facebook, LinkedIn, Flickr, YouTube), social bookmarking sites (e.g., delicious, Connotea, CiteULike), and virtual worlds (e.g., Second Life). An overview of how some of these tools are being used by professional teachers and other CRS subject experts most especially for developing collaborative work are briefly discussed here.

\section{Wiki}

A wiki is a Web page that can be viewed and modified by anybody with a Web browser and access to the Internet. This means that any visitor to the wiki can change its content if they desire. While the potential for mischief exists, wikis can be surprisingly robust, open-ended, collaborative group sites. Wikis permit asynchronous communication and group collaboration across the Internet. Variously described as a composition system, a discussion medium, a repository, a mail system, and a tool for collaboration, wikis provide users with both author and editor privileges; the overall organization of contributions can be edited as well as the content itself. Wikis are able to incorporate sounds, movies, and pictures; they may prove to be a simple tool to create multimedia presentations and simple digital stories. According to The Wiki Way, "“[O]pen editing' has some profound and subtle effects on the wiki's usage. Allowing everyday users to create and edit any page in a Web site .encourages democratic use of the Web and promote content composition by nontechnical users. Because the user interface is familiar a Web page on a personal computer-barriers to modifying wiki pages are minimal. Plus, the results of the users' actions on the content of the site are instantly visible to other users. The best known example of a wiki Web site is Wikipedia, an online dictionary building collaboration.

The implications of wiki for teaching and learning CRS are that Wikis might be the easiest and most effective Web-based collaboration tool in any instructional portfolio. Their inherent simplicity provides students with direct (and immediate) access to a site's content, which is crucial in group editing or other collaborative project activities. According to EDUCAUSE (2005), a wiki's versioning capability can show the evolution of thought processes as students interact with the site and its contents. These collaborative projects help promote "pride of authorship" and owner- 
ship in the team's activities. In addition, wikis are being used as e-portfolios, illustrating their utility as a tool for collection and reflection. Collaboration using a wiki is not limited to students. Faculty can use wikis to collaborate on projects, whether editing a textbook, preparing a journal article, or assembling a syllabus or reading list. Wikis might also prove to be an ideal vehicle for soliciting ongoing input for research or projects where community input can help inform and direct subsequent investigation. The possibilities for using wikis as the platform for collaborative projects are limited only by one's imagination and time. Wiki enabled projects can provide various levels of site access and control to team members, offering a fine-tuning element that enhances the teaching and learning experience.

\section{RSS Feed}

RSS is a technology that is being used by millions of web users around the world to keep track of their favorite websites. In the 'old days' of the web to keep track of updates on a website you had to 'bookmark' websites in your browser and manually return to them on a regular basis to see what had been added. RSS flips things around a little and is a technology that provides you with a method of getting relevant and up to date information sent to you for you to read in your own time. It saves you time and helps you to get the information you want quickly after it was published. RSS stands for 'Really Simple Syndication'. Many people describe it as a 'news feed' that you subscribe to. The benefits of RSS to the teaching and learning of CRS include the fact that RSS solves a problem for people who regularly use the web. It allows you to easily stay informed by retrieving the latest content from the sites you are interested in. You save time by not needing to visit each site individually. You ensure your privacy, by not needing to join each site's email newsletter. The number of sites offering RSS feeds is growing rapidly and includes big names like Yahoo News.

\section{Social Networking Tools}

A social networking service is an online services, platform, or site that focuses on building and reflecting of social networks or social relations among people, e.g., who share interests and/or activities. A social network service essentially consists of a representation of each user (often a profile), his/her social links, and a variety of additional services. Most social network services are web based and provide means for users to interact over the internet, such as e-mail and instant messaging. Online community services are sometimes considered as a social network service, though in a broader sense, social network service usually means an individual-centered service whereas online community services are group-centered. Social networking sites allow users to share ideas, activities, events, and interests within their individual networks. The main types of social networking services are those which contain category places (such as former school year or classmates), means to connect with friends (usually with self-description pages) and a recommendation system linked to trust. Popular methods now combine many of these, with Facebook and Twitter widely used worldwide, Nexopia (mostly in Canada); and Twitter, Facebook, Linedln and Orkut are very popular in India.

Although social networking is possible in person, especially in the workplace, universities, and high schools, it is most popular online. This is because unlike most high schools, colleges, or workplaces, the internet is filled with millions of individuals who are looking to meet other people, to gather and share first-hand information and experiences about cooking, golfing, gardening, developing friendships or professional alliances, finding employment, businessto-business marketing and even groups sharing information about the end of the Mayan calendar and the Great Shift to arrive December 21,2012. The topics and interests are as varied and rich as the story of our world. 
The educational applications of social networking were contained in a report by the National School Boards Association in the US. The report states that almost 60 percent of students who use social networking talk about education topics online and, surprisingly, more than 50 percent talk specifically about schoolwork. Yet the vast majority of school districts have stringent rules against nearly all forms of social networking during the school day even though students and parents report few problem behaviors online (Elison et al. 2007). Social networks focused on supporting relationships between teachers and their students are now used for learning, educator professional development, and content sharing. Cites such as Ning for teachers, Learn Central, TeachSteet and other sites are being built to foster relationships that include educational blogs, eportfolios, formal and ad hoc communities, as well as communication such as chats, discussion threads, and synchronous forums. These sites also have content sharing and rating features. Social networks are also emerging as online yearbooks, both public and private. One such service is My Yearbook which allows anyone from the general public to register and connect. A new trend emerging are private label yearbooks only accessible by students, parents and teachers of a particular school similar to Facebook beginning within Harvard

\section{Purpose of Study}

The purpose of this study was to examine the available ICT web based tools suitable for instructional delivery of CRS. The study was designed primarily to capture the types of ICT web based tools that can be used for instructional delivery in CRS by CRS teachers in secondary school.

This study focuses on the use of ICT as a tool in CRS curriculum by answering the following questions:

1) What is the awareness of the CRS teachers on the available ICT tools for instructional delivery in CRS?

2) What are the ICT tools that are being used in teaching CRS in secondary?

3) What are the obstructions that face teachers in the use of ICT tools?

\section{Methods}

The design of this study involved a quantitative paradigm. This study employed a self-designed questionnaire to obtain descriptive data about the current practice of ICT web based tools use in CRS instructional delivery by secondary school teachers. The study sites were twenty secondary schools randomly selected by the researcher in Lagos State, Nigeria. Statistical software SPSS was used to analyze the data.

\section{Population and Sample}

The sample included teachers teaching CRS in secondary schools across Lagos State, Nigeria. A total of 500 secondary school Christian religious studies teachers were selected from 100 secondary schools in Lagos, Ogun and Oyo states Nigeria. The selection in terms of number from each school varies as there are more CRS teachers in some school than the other. Eventually, a total of 500 CRS teachers were selected which represent the sample for this study.

\section{Instrument}

A self-designed questionnaire by the researcher was used to measure CRS teacher awareness, and types of ICT tools available for instructional delivery in CRS. The questionnaire instrument has three sections: background information, awareness of ICT web based tools use in teaching, types of ICT tools available for use in teaching CRS. The first section asked the participants to provide 
information about gender, teaching level, discipline, and years of teaching practice. The second section gathered information related to the objectives of the study.

This section used a 4-point Likert-rating scale of responses: 1 (never), 2 (sometimes), 3 (often), and 4 (very often). The third section also was desgined to measure the perceptions of ICT use by college instructors. It consists of 12 items. This section also used a 4-point Likert-rating scale of responses ranging from 1 to 4 (strongly disagree, $S D=4$; disagree, $D=3$; agree, $A=2$; and strongly agree, $S A=1)$.

To ensure the validity of the questionnaire, it was given to two experts who are teachers and researchers in CRS in tertiary institutions in Nigeria. Based on the feedback from the expert panel, the researcher updated the survey instrument and made the necessary corrections. The comments and suggestions indicate that the questionnaire has both face and content validity as the items in it relate to the content of what is being measured. Cronbach's alpha test of reliability and internal consistency was conducted on each factor focused in the questionnaire. The results of the Cronbach's alpha revealed awareness of ICT web based tools for teaching CRS $(\alpha=0.77, n=20)$ and available ICT tools for teaching CRS $(\alpha=0.89, n=20)$, which are considered good to excellent by tstandards ( $>.8$ Good, $>.9$ Excellent) set by George and Mallery (2003) .

\section{Procedure}

The researcher with the assistant of some colleagues moved round all the participating schools to administer the instrument. The exercise took two months starting from $10^{\text {th }}$ October to $10^{\text {th }}$ December, 2011. The participants were given ten minutes for the completion of the questionnaire. Responses were collected immediately. A total of 700 questionnaires were administered in all the selected 100 schools, eventually only 500 were useful for data analysis on this study.

\section{Results}

The results in Table 1 reveal that more female (68.2\%) than male $(31.8 \%)$ participated in the study. This implies that there are more female teaching CRS in secondary schools in the three states that the study was conducted. The results in table 1 also indicate that $41.2 \%$ of the participants have between 6-10 years of teaching experience in CRS. This is immediately followed by $32.6 \%$ who have between $0-5$ years of teaching CRS at the secondary school level. A total of $17.6 \%$ have been teaching the subject for between $10-15$ years back while $8.6 \%$ have been teaching the subject at the secondary school for the past 20 years and above. On the class and level being taught by the respondents, the results reveal that more than average participants $(50.2 \%)$ are teaching junior secondary school classes. Moreover, the results indicate that $(19.8 \%)$ are teaching the senior secondary class $1,(16.4 \%)$ are teaching senior class 2 while $(13.6 \%)$ are teaching senior class 3. Furthermore, the results reveal that there were more participants from Lagos State $(40 \%)$ than the other two states Ogun and Oyo states which have (30\%) participants respectively.

Table 1: Bio-Data Information $(\mathrm{N}=\mathbf{5 0 0})$

\begin{tabular}{|l|l|c|}
\hline Gender & Frequency & Percentages \% \\
\hline Male & 159 & 31.8 \\
\hline Female & 341 & 68.2 \\
\hline Total & 500 & 100 \\
\hline
\end{tabular}




\begin{tabular}{|l|r|c|}
\hline Teaching Experience & & \\
\hline $0-5$ years & 163 & 32.6 \\
\hline $6-10$ years & 206 & 41.2 \\
\hline $11-15$ years & 88 & 17.6 \\
\hline 20 years + & 43 & 8.6 \\
\hline Total & 500 & 100.0 \\
\hline Class Taught & & \\
\hline JSS Classes & 251 & 50.2 \\
\hline SSS 1 & 99 & 19.8 \\
\hline SSS 2 & 82 & 16.4 \\
\hline SSS 3 & 68 & 13.6 \\
\hline Total & 500 & 100.0 \\
\hline State & & \\
\hline Lagos & 200 & 40 \\
\hline Ogun & 150 & 30 \\
\hline Oyo & 150 & 30 \\
\hline Total & 500 & 100 \\
\hline
\end{tabular}

\section{CRS Teachers and the Awareness of Web based for Instructional Delivery}

To capture data to answer the research question that focused this objective, the participants were asked to indicate whether or not they were aware of the availability of the Web based tools listed in table 1.

Table 2: Awareness of Web based for instructional delivery $(\mathbf{N}=\mathbf{5 0 0})$

\begin{tabular}{|l|c|l|}
\hline Web Based Tools & Frequency & Percentages \% \\
\hline Email & 500 & 100 \\
\hline Discussion Forum & 50 & 10 \\
\hline Drop Box & 5 & 1 \\
\hline News group & 25 & 5 \\
\hline Blog & 20 & 4 \\
\hline RSS FEEDs & 5 & 1 \\
\hline Face book & 485 & 97 \\
\hline Wiki & 20 & 4 \\
\hline Flikr & 15 & 3 \\
\hline Knowledge System & 5 & 1 \\
\hline
\end{tabular}

The results in Table 2 reveal that all the participants $(100 \%)$ were aware of the availability of email as a web based tools suitable for instructional delivery in CRS. This is followed by facebook which $(97 \%)$ of the participants indicated they were aware of as web based tool for teaching CRS at the secondary school level. The results show further that awareness of the participants in the other web based tools was very low. For instance, only (10\%); indicated been aware of discussion forum as a web based tool useful for CRS instructional delivery. Others followed in this order: news group (5\%), blog and wiki (4\%) each, flikr (3\%) while dropbox, RSS feeds, and knowledge 
system all have (1\%) each. The results imply that awareness of the CRS teachers is high on the suitability of email and facebook than other web based tools.

\section{Types of Web Based Tools for Instructional Delivery in CRS}

To capture data to answer the research question that focused this objective, some types of Web based tools were listed and the participants were asked to indicate the one they have attempted to use for instructional delivery in CRS. The result is presented in table 3.

Table 3: Some Web based Tools for Instructional Delivery in CRS $(N=500)$

\begin{tabular}{|l|c|l|}
\hline Web Based Tools & Frequency & Percentages \\
\hline Email & 300 & 60 \\
\hline Discussion Forum & 2 & 0.4 \\
\hline Drop Box & - & - \\
\hline News group & - & - \\
\hline Blog & 1 & 0.2 \\
\hline RSS FEEDs & - & - \\
\hline Face book & 15 & 3 \\
\hline Wiki & - & - \\
\hline Flikr & - & - \\
\hline Knowledge System & - & - \\
\hline
\end{tabular}

The results in the table indicate the type of web based tools that CRS teachers have attempted using in teaching CRS. A considerable percentage (60\%) indicated they have attempted using email. (3\%) indicated they have used Facebook while $(0.4 \%)$ have used discussion forum and $(0.2 \%)$ used blog. None of the participants have attempted using web based tools like drop box, newsgroup, RSS feeds, wiki, Flikr and knowledge system. These results may be as a result of the low awareness of these tools and their suitability for the teaching of CRS.

\section{Obstructions in the Use of Web Based Tools by CRS Teachers}

To capture data on this objective in order to answer the relevant research questions, the participants were asked to indicate which of the factors listed obstruct their use of the listed web based for instructional delivery. The result is presented in table 4 .

Table 4: Hindrance to Use of Web based tools by CRS Teachers $(N=500)$

\begin{tabular}{|l|c|c|}
\hline Factors & Frequency & Percentages \\
\hline Lack of Awareness & 350 & 70 \\
\hline Lack of skills to apply the tools & 300 & 60 \\
\hline Lack of access & 300 & 60 \\
\hline Cost of access & 299 & 59.8 \\
\hline Electricity failure rate & 500 & 100 \\
\hline Lack of Internet connectivity in schools & 360 & 72 \\
\hline
\end{tabular}

The most common obstruction to the use of the web based tools for CRS instructional delivery is electricity failure rate which was indicated by all the participants $(100 \%)$. This is followed by lack of Internet connectivity indicated by $(72 \%)$ of the participants. Following this is lack of 
awareness which was indicated by $(70 \%)$ of the participants. The following obstacles: lack of skills, lack of access followed with $(60 \%)$ respectively while cost of access was indicated by $(59.8 \%)$ of the participants.

\section{Summary and Conclusion}

The results imply that awareness of the CRS teachers is high on the suitability of email and Facebook than other web based tools. Some participants $(60 \%)$ have attempted using email to teach CRS while none of the participants have attempted using web based tools like drop box, newsgroup, RSS feeds, wiki, interactive white board and knowledge system. The most common obstruction to the use of the web based tools for CRS instructional delivery is electricity failure rate.

\section{Recommendations}

Based on the above findings reveal in this study, the following are recommended. That the government should consider finding alternative to electricity failure rate as the study has indicated this as the most prominent factor limiting their awareness of the available web based tools suitable for teaching CRS. There is need to create more awareness on those tools the CRS teachers indicated having limited awareness of. This may inform the organising of a workshop where the

entire participants will be connected with the Internet. Through this, they will be exposed to those tools and practically see how they can be used.

\section{References}

Becta. (2004). Embeding ICT at secondary: Use of interactive whiteboards in religious education. The Department for Education and Skills, UK.

EDUCAUSE. (2005). Seven things you should know about wikis. EDUCAUSE Learning Initiative. Accessed 19 June 2011 from http://net.educause.edu/ir/library/pdf/ELI7004.pdf

Fisher, T. (2005). Technology means nothing without humans. Retrieved 09 January, 2012 from http://www.tes.co.uk/search/story/?story id=2082994

George, D., \& Mallery, P. (2003). SPSS for Windows step by step: A simple guide and reference (4th ed.). Boston: Allyn \& Bacon.

Klistrom, L. (2009). Blogging: Five advantages of teaching using a blog. Available at http://www.associatedcontent.com/article/1644306/blogging_five advantages_of tea ching pg3.html?cat=15

Lubis, M. A., Embi, M. A., Yunus, M. M., \& Wekke, I. S. (2009). The application of multicultural education and applying ICT on Pesantren in South Sulawesi, Indonesia. WSEAS Transactions on Information Science and Applications, 6(8), 1401-1411.

March, T. (2005). The new WWW: Whatever, whenever wherever. Educational Leadership, 63(4), 14-19.

Milken Exchange on Education Technology. (1999). Will new teachers be prepared to teach in a digital age? Santa Monica: Milken Family Foundation. Retrieved January 09. 2012, from http://www.mff.org/pubs/ ME1544)df.

Ofsted (Office for Standards in Education). (2005). Embedding ICT in schools - A dual evaluation exercise. Office for Standards in Education. London: HMSO.

Schiller, J., \& Tillett, B. (2004). Using digital images with young children: Challenges of integration. Early Child Development and Care, 174(4), 401-414.

Strenski, E. (1998). Using the internet (e-mail, mailing list, WWW) as a learning tool. Accessed 5 January 2011 from https://eee.uci.edu/faculty/strenski/JSsummer.html 
Yusuf, M. O. (2000). Information technology. New dimensions to the development of teacher education programme in Nigeria. Nigeria Journal of Computer Literacy, 4 (1), 25-40.

\section{Biographies}

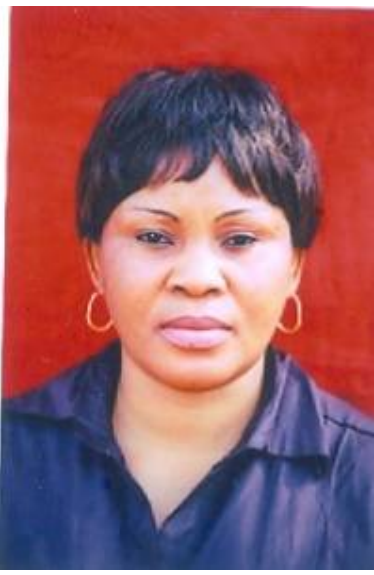

Ganiat Adebola KOSOKO-OYEDEKO is a lecturer in the School of Arts and Social Sciences, Michael Otedola College of Primary Education (Mocped) Noforija Epe, Lagos State, Nigeria. She is also a Ph.D. student at the University of Ibadan, Faculty of Education, Teacher Education Department, Ibadan, Oyo State, Nigeria. She has supervised many undergraduate students.

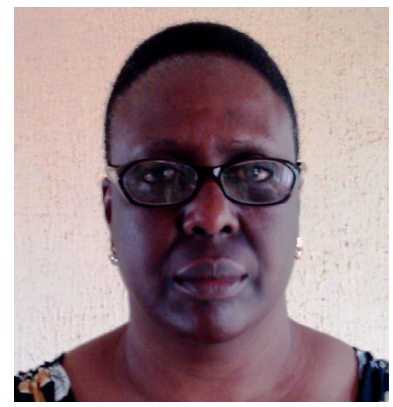

Dr. Gloria Olushola ADEDOJA is a lecturer in the Educational Technology unit in the Faculty of Education, Teacher Education Department at the University of Ibadan, Oyo State, Nigeria. She has supervised a lot of students both at undergraduate and post graduate level. She is currently working on "The integration of mobile learning into the teaching and learning process in distance learning education in Nigeria." 